\title{
Sôbre a determinação do Nitrogênio, do Fósforo e do Potássio no mesmo extrato
}

\author{
E. MALAVOLTA, J. P. ARZOLLA e H. P. HAAG \\ Cadeira de Química Orgânica e Biológica \\ E. S. A. "Luiz de Queiroz" U. S. P. - Piracicaba
}

\section{INDICE}

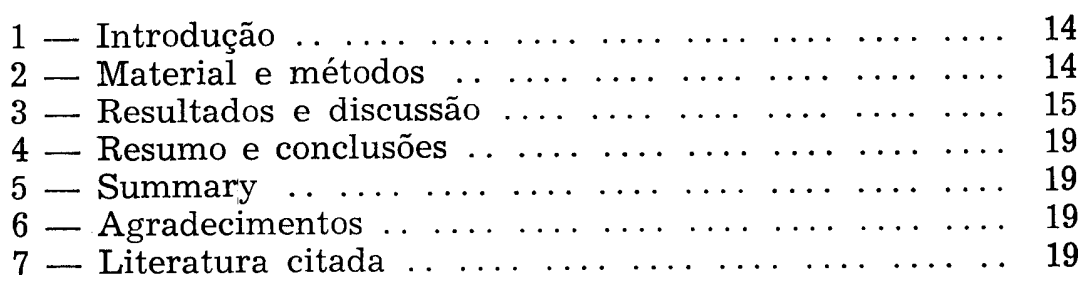




\section{INTRODUÇÃO}

DAMLE e KRISHNAN (1954) descreveram um método para a determinação do nitrogênio e fósforo totais no mesmo extrato, usando na digestão ácido sulfúrico e água oxigenada a 30 por cento.

No presente trabalho adaptamos a marcha analítica para a determinação do nitrogênio, fósforo e potássio contido em tecidos vegetais. Isto foi feito para facilitar a dosagem dêsses três macronutrientes - os mais importantes para o metabolismo das plantas superiores.

\section{MATERIAL E MÉTODOS}

2.1. Obtenção do extrato. Coloca-se em um balão de Kjeldahl de $30 \mathrm{ml}$ - ou num tubo de ensaio com tamanho correspondente $-250 \mathrm{mg}$ de material sêco e triturado. Junta-se $4 \mathrm{ml}$ de H2SO4 concentrado, cobre-se frouxamente e leva-se para um banho de areia aquecido por bico de gás. Digere-se a princípio com chama fraca e, depois que o material se dissolveu, aquece-se fortemente até ao aparecimento de fumos; resfria-se durante meio minuto e junta-se, deixando correr pelas paredes, 4 gotas de Perhydrol Merck. Torna-se a cobrir os tubos frouxamente continuando o aquecimento; de 15 em 15 minutos juntam-se mais 4 gotas de Perhydrol; a digestão prossegue até que o extrato fique completamente incolor; em geral são necessárias 24-30 gotas de água oxigenada. Continuar o aquecimento durante meia hora mais; esfriar, diluir com água e aquecer à ebulição durante 3 minutos. A digestão em geral se completa em 3-4 horas. Filtrar para um balão de $50 \mathrm{ml}$ e completar ao volume.

2.2. Determinação do nitrogênio. No método de DAMLE e KRISHNAN (1954) o nitrogênio era determinado mediante microdestilação da amônia formada. Verificamos, porém, que resultados idênticos podiam ser conseguidos fazendo-se nesslerização direta do extrato; é necessário, entretanto, usar uma quantidade relativamente grande $(10 \mathrm{ml})$ do reagente para compensar a acidez da amostra. A determinação é feita pipetando-se uma alíquota de 1 a $5 \mathrm{ml}$ para um balão de $100 \mathrm{ml}$, juntando-se mais ou menos $50 \mathrm{ml}$ de $\mathrm{H} 2 \mathrm{O}$ destilada e agitando-se; 
adiciona-se então $10 \mathrm{ml}$ do reagente de Nessler, completa-se ao volume, agita-se e depois de 20 minutos lê-se a densidade ótica num colorímetro fotoelétrico com filtro azul. Simultâneamente faz-se uma prova em branco e vários padrões.

2.3. Determinação do fósforo. E' feita colorimètricamente, com base na conhecida reação do azul de molibdênio. Uma alíquota de $1-5 \mathrm{ml}$ é pipetada para um balão de $100 \mathrm{ml}$ a que se junta mais ou menos $50 \mathrm{ml}$ de $\mathrm{H} 2 \mathrm{O}$ destilada; adiciona-se $5 \mathrm{ml}$ de molibdato de amônio a 2,5 por cento em H2SO4 $10 \mathrm{~N}$, completa-se ao volume e agita-se; junta-se $2 \mathrm{ml}$ de $\mathrm{SnCl} 2$ a $2 \%$ agita-se e 10 minutos depois faz-se a leitura (filtro vermelho).

2.4. Determinação do potássio. Devido à simplicidade de técnica escolhemos o método volumétrico do cobaltinitrito para a determinação do potássio. Como $\odot \mathrm{NH} 4+$ dá um precipitado com êsse reagente, torna-se necessário eliminá-lo prèviamente; isto se faz com água régia. A marcha operatória é a seguinte : $10-25 \mathrm{ml}$ de alíquota (entre 0,2 e $2 \mathrm{mg}$ de $\mathrm{K}$ ) são transferidas para uma cápsula de porcelana de $50 \mathrm{ml}$ de capacidade que é posta em banho dágua para evaporar; quando no fundo da cápsula houver apenas ácido sulfúrico com substâncias em solução, retira-se a mesma e junta-se $4-5 \mathrm{ml}$ de água régia que deve correr pelas paredes. Cobre-se com vidro de relógio e leva-se para evaporar sôbre chapa quente; quando não houver mais reação violenta, deixa-se as cápsulas semidescobertas, mantendo-as sôbre a chapa quente até secar; passa-se $1 \mathrm{ml}$ de HNO3 concentrado pelo vidro de relógio recolhendo o ácido na cápsula; seca-se em banho dágua fervente e, se necessário, filtra-se para outra cápsula retomando-se prèviamente com 2-3 $\mathrm{ml}$ de água destilada. A seguir o potássio é precipitado pelo cobaltinitrito, seguindo-se a marcha usual.

\section{RESULTADOS E DISCUSSÃO}

3.1. Nitrogênio. 'Inicialmente procuramos comparar a recuperação conseguida mediante microdestilação com a obtida por nesslerização direta (10 $\mathrm{ml}$ do reativo de Nessler). Os resultados foram os seguintes : 


\begin{tabular}{c|c|c}
\hline \multirow{2}{*}{ Material } & \multicolumn{2}{|c}{ Leitura cc lorimétrica } \\
\cline { 2 - 3 } & Destilação & $\begin{array}{c}\text { Nesslerização } \\
\text { diréta }\end{array}$ \\
\hline $10 \mathrm{ml}$ padrão (*) & 7,75 & 8,00 \\
$2 \mathrm{ml}$ extrato (**) & 10,25 & 10,55 \\
\hline
\end{tabular}

(*) $1 \mathrm{ml}$ padrão $=0,012 \mathrm{mg} \mathrm{N}$

(**) $250 \mathrm{mg}$ folha de cana de açúcar em $50 \mathrm{ml}$

Os dados acima são médias de várias determinações bem concordantes. Vê-se, portanto, que a destilação não é necessária; pode-se determinar o nitrogênio total por nesslerização direta duma alíquota apropriada. A coloração se desenvolve bem sendo as soluçöes perfeitamente transparentes.

Como dissemos no início, a acidez do extrato deveria provàvelmente influir na coloração desenvolvida, porque iria neutralizar em parte a acidez do reagente de Nessler. Foram ensaiadas, então, várias quantidades do Nessler, chegando-se à conclusão de que $10 \mathrm{ml}$ é a quantidade a usar. Resultados típicos são os seguintes :

\begin{tabular}{lcc}
\hline Material & ml reag. Nessler & $\begin{array}{c}\text { Leitura co- } \\
\text { lorimétrica }\end{array}$ \\
\hline $2 \mathrm{ml}$ extrato & 5 & 9,0 \\
$2 \mathrm{ml}$ extrato & 10 & 10,5 \\
$2 \mathrm{ml}$ extrato & 15 & 10,5 \\
$4 \mathrm{ml}$ extrato & 10 & 21,5 \\
$4 \mathrm{ml}$ extrato & 15 & 21,25 \\
\hline
\end{tabular}

Foi ensaiada depois a recuperação obtendo-se valores como os que seguem :

Recuperação do nitrogênio

\begin{tabular}{lcc}
\hline Material & $\begin{array}{c}\mathrm{mg} \mathrm{N} \\
\text { encontradas }\end{array}$ & Recuperação \\
\hline 1. $10 \mathrm{ml}$ padrão & 0,100 & 6 \\
2. $2 \mathrm{ml}$ extrato & 0,131 & - \\
3. $1+-2$ & 0,229 & 99 \\
4. $4 \mathrm{ml}$ extrato & 0,268 & 102 \\
$5 . \quad 1+4$ & 0,362 & 98 \\
\hline
\end{tabular}


Finalmente, para testar a validez do método comparâmo lo com o macro Kjeldahl. Os resultados das determinações feitas em diferentes folhas de fórmio (Phormium tenax) são dados a seguir :

Comparação de métodos

\begin{tabular}{|c|c|c|}
\hline Amostra & $\begin{array}{l}\text { Nesslerização } \\
\text { diréta }\end{array}$ & $\begin{array}{c}\text { Macro } \\
\text { Kjeldahl }\end{array}$ \\
\hline & \multicolumn{2}{|c|}{$\mathrm{N} \%$} \\
\hline 1 & 1,20 & 1,10 \\
\hline 2 & 0,77 & 0,80 \\
\hline 3 & 0,75 & 0,79 \\
\hline 4 & 0,89 & 0,81 \\
\hline 5 & 0,93 & 1,00 \\
\hline
\end{tabular}

Vê-se no quadro acima, que a técnica ora em discussão dá resultados comparáveis aos obtidos com a macrodeterminação.

3.2. Fósforo. Como na preparação do extrato usam `s substâncias altamente oxidantes - ácido sulfúrico e $\mathrm{H} 2 \mathrm{O} 2$ a 30 por cento apareceu logo a possibilidade de interferência na dosagem colorimétrica do fósforo, uma vez que, a mesma se baseia na redução (pelo cloreto estanhoso) do complexo de fosfomolibdato de amônio. Verificamos logo que a dificuldade podia ser contornada usando-se $2 \mathrm{ml}$ da solução de cloreto estanhoso a $2 \%$. E' o que demonstram os dados seguintes :

\begin{tabular}{lcc}
\multicolumn{3}{c}{ Recuperação do fósforo } \\
\hline \multicolumn{1}{c}{ Material } & $\begin{array}{c}\text { mg } P \\
\text { encontradas }\end{array}$ & Recuperação \% \\
\hline $1.1 \mathrm{ml}$ padrão $\left(^{*}\right)$ & 0,025 & - \\
2. $2 \mathrm{ml}$ padrão & 0,050 & - \\
3. $1 \mathrm{ml}$ extrato & 0,006 & - \\
4. $2 \mathrm{ml}$ extrato & 0,012 & 100 \\
$5.3 \mathrm{ml}$ extrato & 0,019 & 105 \\
$6.1+3$ & 0,030 & 96 \\
$7.2+4$ & 0,059 & 95 \\
\hline
\end{tabular}

(*) $0,4394 \mathrm{~g} \mathrm{KH} 2 \mathrm{PO} 4$ em $1.000 \mathrm{ml} ; 250$ em $1.000 ; 1 \mathrm{ml}=0,025$ mg P.

3.3 Potássio. Na determinação do potássio usamos para fator de conversão: $1 \mathrm{ml} \mathrm{KMnO4} 0,05 \mathrm{~N}=0,310 \mathrm{mg}$ de $\mathrm{K}$. Como 
já foi mencionado, em vista do método analítico usado para a determinação do potássio, havia necessidade de eliminar os sais amoniacais formados durante a digestão a fim de não se ter resultados errôneamente altos. A eficácia da eliminação do sulfato de amônio com água régia se acha ilustrada na tabela seguinte : guir :

A recuperação do potássio foi aceitável como se vê a seEliminação dos sais amoniacais com água régia

\begin{tabular}{|c|c|c|}
\hline \multirow{2}{*}{ Material } & \multicolumn{2}{|c|}{$\mathrm{ml} \mathrm{KMn} 04 \quad 0,05 \mathrm{~N}$ gastos } \\
\hline & Marrha usual & Água régia \\
\hline 1. $20 \mathrm{ml}$ extrato & 2,6 & 2,2 \\
\hline 2. $2 \mathrm{mg} \mathrm{K}$ & 7,0 & 7,1 \\
\hline 3. $4 \mathrm{mg} \mathrm{K}$ & 14,1 & 14,1 \\
\hline 4. $1+2$ & 9,6 & 9,3 \\
\hline 5. $5,5 \mathrm{mg} \quad(\mathrm{NH} 4) 2 \mathrm{SO} 4$ & 5,1 & 0,1 \\
\hline $6.1+5$ & 6,7 & 2,3 \\
\hline
\end{tabular}

Recuperação do potássio

\begin{tabular}{cccc}
\hline Material & $\begin{array}{c}\mathrm{mg} \mathrm{K} \\
\text { existertes }\end{array}$ & $\begin{array}{c}\mathrm{mg} \mathrm{K} \\
\text { encontradas }\end{array}$ & Recuperação \% \\
\hline 1. $20 \mathrm{ml}$ extrato & - & 0,682 & - \\
2. $5 \mathrm{ml}$ solu. & - & & 105 \\
padrão K2SO4 & 2,0 & 2,1 & \\
3. 10 ml solu. & & & 107 \\
padrão K2SO4 & 4,0 & 4,3 & 106 \\
$4.1+5$ & 2,682 & 2,883 & \\
\hline
\end{tabular}

\section{RESUMO E CONCLUSÕES}

No presente trabalho descreve-se a determinação do nitrogênio, fósforo e potássio em tecidos vegetais no mesmo extrato. A digestão é feita oxidando-se $250 \mathrm{mg}$ de material sêco e triturado com ácido sulfúrico concentrado e água oxigenada a 30 por cento. 
O nitrogênio é determinado por nesslerização direta usando-se uma alíquota de $1-5 \mathrm{ml}$ que depois de diluida a $50 \mathrm{ml}$ recebe $10 \mathrm{ml}$ de reagente de Nessler; completa-se a $100 \mathrm{ml}$ e depois de 20 minutos lê-se a extinção.

Uma alíquota de $1-5 \mathrm{ml}$ presta-se para a determinação do fósforo depois de reduçãn do fosfomolibdato com $2 \mathrm{ml}$ de $\mathrm{SnCl} 2$ a $2 \%$.

O potássio é determinado volumètricamente pelo cobaltinitrito numa alíquota $\sqrt{ }$ e $10-25 \mathrm{ml}$, depois, da destruição dos sais amoniacais com $4 \mathrm{ml}$ de água régia.

\section{SUMMARY}

The determination of total nitrogen, phosphorus, and potassium in plant material can be carried out in a common extract prepared with sulphuric acid and 30 per cent hydrogen peroxide.

Nitrogen is estimated by direct nesslerization of a suitable aliquot $(1-5 \mathrm{ml}$ of the $50 \mathrm{ml}$ extract made out of $250 \mathrm{mg}$ of dried material); in order to avoid excessive acidity, $10 \mathrm{ml}$ of Nessler's reagent should be employed.

An aliquot of 1-5 ml suffices for the colorimetric determination of phosphorus by the molybdenum method; to reduce the phosphomolybdate complex $2 \mathrm{ml}$ of a $2 \% \mathrm{SnCl} 2$ soln are necessary.

Potassium is determined by the cobaltinitrite method after elimination of ammonium salts with the aid of aqua-regia.

\section{AGRADECIMENTOS}

Os autores agradecem : 1) Ao Prof. J. Mello Moraes pelas facilidades apresentadas em seu laboratório; 2) Ao Prof. R. A. Catani por sugestões apresentadas.

\section{LITERATURA CITADA}

DAMLE, S. P. and P. S. KRISHNAN, 1954 - One step digestion procedure for the estimation of total phosphorus and nitrogen in mould tissue. Anal. Chim. Acta. 11 (3) : 225-228. 
. 